\title{
Short communication \\ A scientometric examination of the performance of water research in South Africa
}

\author{
IM Jacobs ${ }^{1 *}$, A Pouris ${ }^{2}$ and D Naidoo \\ 'Water Research Commission, Private Bag X03, Gezina, Pretoria, 0031, South Africa \\ ${ }^{2}$ Institute for Technological Innovation, University of Pretoria, Pretoria, South Africa
}

\begin{abstract}
Regular assessment of the state of water research and development (R\&D) in South Africa is a necessary component of science policy and successful R\&D implementation. Among others, effective R\&D has a direct impact on water resource management and promotes training and capacity building initiatives. Much of the country's water research is carried out under the auspices of the Water Research Commission (WRC), a national public entity established by the Water Research Act (Act No. 34 of 1971). Water R\&D is carried out by universities, public research institutions and science councils as well as the private sector. A scientometric examination of South Africa's research and development performance indicates that while the water research and development community is small, it is highly productive. The analysis indicates that the South African contribution to the global share of water-related papers in journals indexed by the ISI (now Thomson Reuters Web of Science) is more than 3 times the average for all disciplines in the country, and that South Africa ranks $19^{\text {th }}$ in the world in the domain of 'Water Resources'. A study of the patent data further indicates a much higher than average conversion of knowledge to products as indicated by the water-related patent/total patent ratios.
\end{abstract}

Keywords: scientometrics, water sector, research, R\&D, South Africa, Water Research Commission (WRC), publication, patent

\section{INTRODUCTION}

The need for a national water research agenda has been articulated by academics and policy-makers alike as the evidencebased solution to inform water policy and ultimately address the complex water challenges we are faced with today. However, in order to facilitate the production of relevant water research that speaks to the needs of a country we first have to take stock of its research inputs (budget expenditure for example), outputs (publications and patents for example) and areas of focus, in order to determine critical gaps in $R \& D$ and capacity. Effectively, we need a comprehensive assessment of the state of water R\&D.

The Organisation for Economic Cooperation and Development (OECD) provides a useful definition of research and development $(\mathrm{R} \& \mathrm{D})$, which will be adopted in this paper. 'Research and experimental development comprise creative work undertaken on a systematic basis in order to increase the stock of knowledge, including knowledge of man, culture and society, and the use of this stock of knowledge to devise new applications' (OECD, 2002 p. 28).

Scientometrics is used internationally for monitoring and assessment purposes. Despite its limitations, the field of scientometrics tells us much about the health of a country's national innovation system. Monitoring and evaluating the various facets of the scientific enterprise is a necessary and integral part of science policy. Rising costs of research and development and competing disciplinary claims for financial resources

To whom all correspondence should be addressed.

ifir +27 12 330-9014; fax: +27-12-331-7625;

e-mail: ingaj@wrc.org.za

Received 30 May 2013; accepted in revised form 3 September 2014. require intelligent allocation of resources, which presupposes knowledge of the activities and performance of the innovation system. Through this approach, we can measure the availability of research with the necessity and impact thereof.

One of the most efficient and objective methods of assessing research and innovation performance is through indicators. Disciplinary and national assessments (Rojo et al., 2005; Dastidar et al., 2005; Pouris, 2005; Jeenah et al., 2008) based on quantitative indicators are used internationally in support of policy development. There is a growing awareness of the advantages of basing opinions and subsequent policy choices on quantitative criteria. Science policy reviews would seem inconceivable today without recourse to existing indicators. Disciplinary assessments are used as benchmarks for the identification of effectiveness of policy instruments, for the support and justification of funding to political authorities, for identification of international collaborators, centres of excellence, and so on.

Probably the most often used indicators for disciplinary assessments are those accruing from bibliometrics and patent analyses. In bibliometrics the number of publications in a field is considered as an indicator of research activity. The philosophy underlying the use of bibliometric indicators as performance measures has been summarised in De Solla Price's statement that publication is not just an indicator but, in a very strong sense, the end product of creative effort for those who are working at the research front (De Solla Price, 1975). In the same way in which scientific articles are accepted as a legitimate reflection of scientific research, patents are accepted as a reflection of technological achievements. Griliches (1990) has pointed out that patent statistics are a unique source to analyse the process of technical change. It is arguably the most comprehensive indicator measuring the quantity of available 
data, accessibility, and potential industrial, organisational, and technological detail.

This paper outlines bibliometric and patent analyses in an attempt to provide a quantitative account of key R\&D trends in the South African (SA) water sector. The broader aim is to inform a larger project, led by the SA Water Research Commission (WRC) that will function as the dedicated reporting mechanism and critical appraisal of water R\&D trends in the country. The broader project will contribute to, and ultimately inform, the sector's knowledge base on water R\&D in South Africa and provide empirical material for additional research on policy, programmes, capacity, geographic spread and financing issues related to water $\mathrm{R} \& \mathrm{D}$. The primary aim of this paper is therefore to provide the starting picture of the state of play in water R\&D with a focus on research outputs.

\section{METHOD}

Currently, scientometric indicators are published routinely to inform the relevant authorities of the state of science, technology and innovation internationally. In the United States of America the National Science Foundation (NSB, 2010) uses indicators to monitor the health of American science and technology on a continuous basis; in Europe the European Commission (EC, 1997) uses similar approaches in order to monitor the health of the European innovation system; the Observatoire des Sciences et des Techniques (OST, 2008) in France produces the biennial report 'Science and Technology Indicators' and the Organisation for Economic Cooperation and Development (OECD, 2010) uses indicators for monitoring and comparative purposes.

In this paper we develop bibliometric and patent indicators for water research and invention in South Africa.

\section{Bibliometric analysis}

Bibliometric analysis, the quantitative study of the research system, is based mainly on publication indicators. In bibliometrics the number of publications in a field is considered as an indicator of research activity and the citations as indicators of impact. Bibliometric analysis therefore uses data on numbers and authors of scientific publications and on the citations therein to measure the 'output' of individuals/research teams, institutions, and countries, to identify national and international networks, and to map the development of new fields of science and technology.

Most bibliometric data come from commercial companies or professional societies with the main general source being the citation databases initiated by the Institute for Scientific Information (ISI) (now Thomson Reuters Web of Science) in the United States.

Bibliometrics is currently its own scientific discipline within the broad discipline of scientometrics. There are a number of journals covering the field, among which are the International Journal of Scientometrics and the Journal of the Association for Information Science and Technology. Bibliometric assessments have a number of advantages. They are repeatable and verifiable exercises and are not dependent on the choice of experts and their opinions which may vary as the choice of the participants changes in peer reviews (Pouris, 1988). Probably their most important advantage is that they allow for comparisons among different scientific disciplines and different countries. Both types of comparisons are not possible through peer review approaches as it is almost impossible to find peers with expertise in different scientific fields and knowledge of the research systems in different countries.
Hence, bibliometrics provide a unique way to identify 'revealed' research priorities in a country or region.

Thomson Reuters (formerly the Institute for Scientific Information (ISI)) Web of Science (WoS) databases (Science Citation Index Expanded, Social Sciences Citation Index and Arts and Humanities Citation Index) are the most often used for these types of investigations. The combined databases comprehensively cover the most prestigious journals in the world in all fields of research endeavour and constitute a unique information platform for the objectives of this effort. The most important advantage of the WoS journals is that they constitute the most important (in terms of impact) journals in the world.

In South Africa the Department of Higher Education and Training (DHET) has identified the WoS-indexed journals for subsidy purposes, in addition to those appearing on the list of DHET-accredited journals (which have undergone a local approval process and may not necessarily be indexed by WoS). Universities receive approximately R120 000 (US\$13 000) for each article they produce, and also give incentives to their researchers to publish in WoS-indexed journals. Consequently, it is expected that the databases will cover not only the most important South African water-related research but the majority of it as well.

Thomson Reuters produces a number of different databases. The National Science Indicators (NSI) database provides summary statistics that reflect research performance for more than 100 countries in the world. In the Deluxe version of NSI, papers from each country are divided into 105 fields in the sciences, social sciences and arts and humanities.

The WoS database assigns journals indexed to scientific categories. The water-related journals are grouped under the title 'water resources' in the Science Citation Index (SCI). The group includes 110 journals. These 110 journals can be considered as the 'core' journals in the field of water research. There may be articles that exist that relate to water research that are not published in the core journals. However, the most important and highest impact water literature will be that published in the core journals and, hence, this analysis aimed to identify and analyse South Africa's contribution to the core water research literature. The South African journal Water SA forms part of the set of journals covered in this study.

For the current investigation we used the WoS databases in order to develop relevant indicators. The indicators reported for the assessment are the country's contribution in terms of the number of publications in the international literature, the country's share in the world literature, the activity index and the relative citation index. The activity index is defined as the ratio of the country's share of the world publication output in a given field to the country's share of the world publication output in all science fields. An activity index of 1 indicates that the country's research output in the given field corresponds to the world average; an indicator larger than 1 reflects a higher than average emphasis in the field and vice versa. Similarly, a relative citation index above 1 indicates that the country's publications in the particular field attract higher than average citation rates and an index of less than 1 indicates that the field attracts below-average citation rates.

The research performance of the country was analysed according to different time periods. Time series for the period 1981-2010 were used in order to show how the country's research performance changed over time. For identification of institutional performances we used the period 1999-2010 (more recent contributions) and for international and cross-disciplinary comparisons we used data from the period 1996-2010. 
A shorter period was chosen for disciplinary comparisons than for institutional comparisons as disciplinary changes may be faster than institutional ones.

\section{Patent analysis}

Statistics on patents constitute an important output indicator for innovation systems. The global data concern the number of patents applied for or granted via national, European, American and other authorities, broken down by country of application and country of residence of the applicant. The main information that can be drawn from patent documents relates to the type of technology covered by the claim, the name and nationality of the inventor (individual, government agency, private corporation), links between a new patent and knowledge in earlier ones and scientific publications, the economic sector where the invention originated, and the fields and markets covered by the patents.

Patent indicators are used in order to identify technological strengths and weaknesses of corporations, countries, etc., and to analyse the rate and direction of technical change. Patent analysis possesses a number of strengths that facilitates its universal use as a scientometric tool. Patent indicators are highly reliable because they are well defined and unambiguous. They facilitate detailed categorisation and, hence, make possible the study of scientific and technological fields and sub-fields. Finally, patent analysis allows for international comparisons. The OECD provides guidelines for the use of patent analyses (OECD, 1994).

Patent analysis - within the science and technology (S\&T) context - is used to measure inventive performance, diffusion of knowledge and internationalisation of innovative activities - across countries, firms, industries and technology areas. For example, Porter et al. (1999) argue that patent indicators are the most appropriate for defining the innovative capacity of countries and that international patenting strongly correlates with alternative measures of innovative output, such as the number of scientific journal articles, and also with outcome measures such as a country's market share in high-technology industries.

Although patents facilitate the development of a number of useful indicators they have a number of drawbacks. Patented inventions are not necessarily all of the inventions produced in a country or organisation. Many inventions are not patented because there are other barriers to entry (e.g., lack of brand names among the competitors), because inventors may undertake other measures of protection (e.g. the encapsulation of products in epoxy resin to deter imitation) or because inventors consider that the invention will be profitable even if imitators may appear in the foreseeable future. Similarly, high costs of application or monitoring infringement as well as lack of appreciation may limit the number of patents from a particular country or organisation.

For the purposes of this investigation we developed patent indicators from the United States Patent and Trademark Office (USPTO). The USA is the largest market for technology and, hence, the majority of technology inventors aim to protect their inventions there.

\section{RESULTS AND DISCUSSION}

\section{South Africa's overall ranking}

As indicated in Fig. 1, water research in South Africa produced 677 articles during the period 2006-2010 placing the

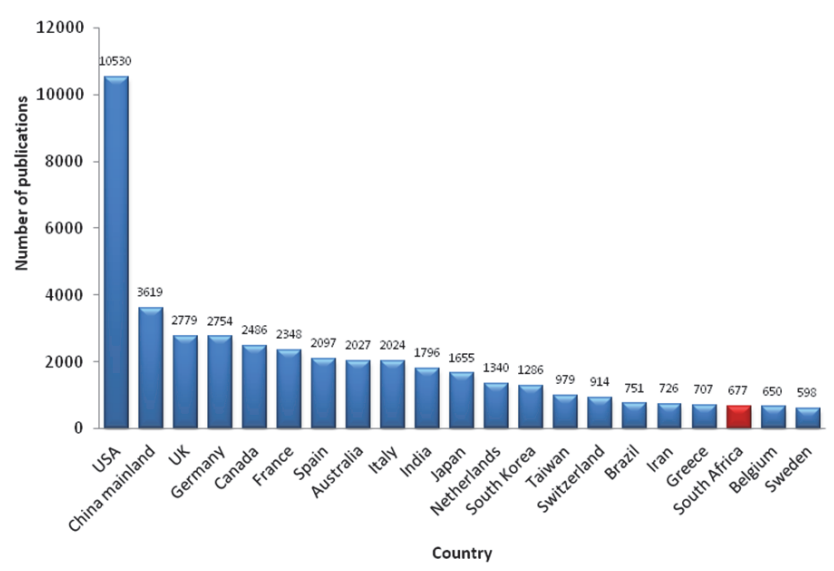

Figure 1

Number of water-related publications per country between 2006 and 2010

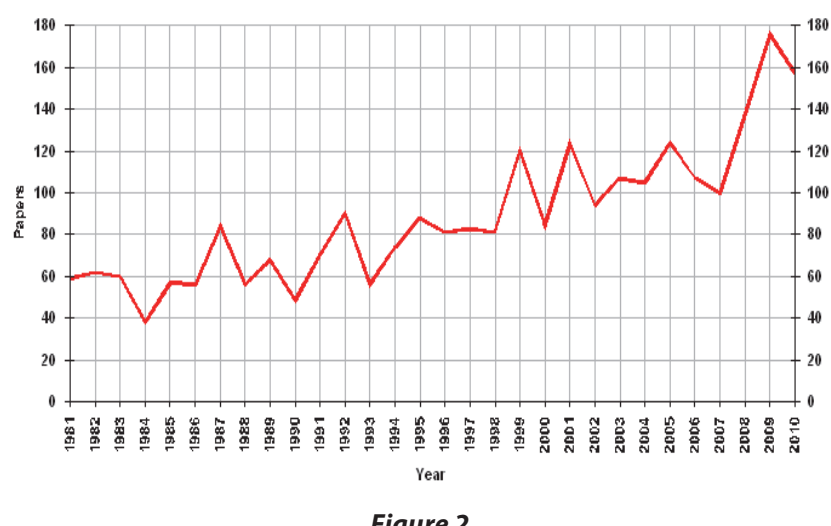

Figure 2

Number of SA water research publications 1981-2010

country $19^{\text {th }}$ in the world in terms of total article output. This performance sets the country's water research output above the average for all scientific disciplines, ranking $33^{\text {rd }}$. The study also revealed that the water field is performing above expectation in comparison to the country's research size (see activity index in Table 1). It can be argued that the focused support by a dedicated national water R\&D agency, the WRC, is a key contributor to this success. However, Fig. 1 shows that a number of countries with smaller populations, like Canada and Australia, or with smaller gross domestic products (GDP) per capita, like India and Brazil, produce more research publications than South Africa.

\section{Research publications}

Figure 2 shows the number of water research publications with at least 1 author with a South African address for the period 1981-2010. South African researchers were producing approximately 60 publications per year at the beginning of this period. During the 2000s the number increased to around 100 publications per year and in 2009 the number jumped to just below 180 publications.

Figure 3 shows the South African share of world water research publications. The share appears to have declined from above $3 \%$ at the beginning of the period to $1.69 \%$ in 2010 . Given that the total number of South African water research publications increased over this period, the declining share can be 


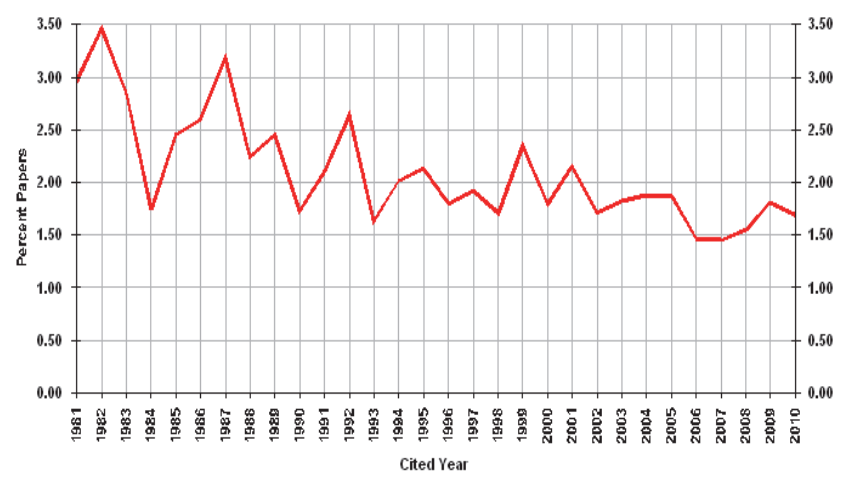

Figure 3

Share of world water research publications contributed by SA 1981-2010

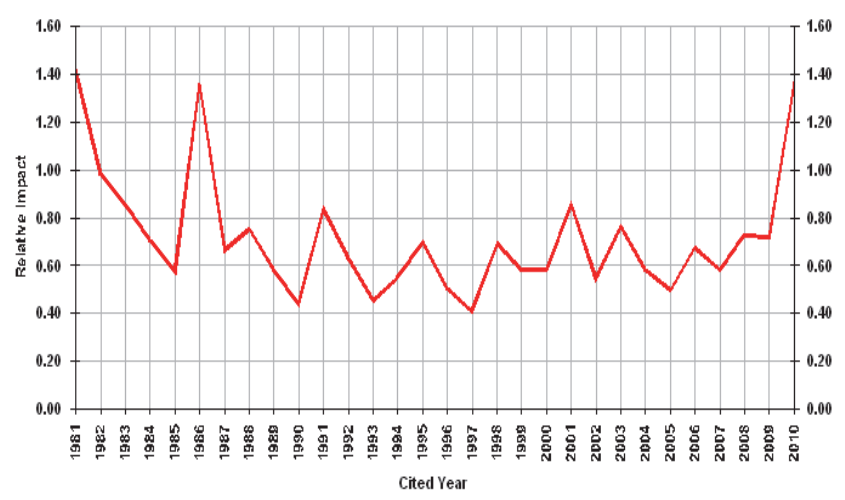

Figure 4

Relative impact (relative citation index) of SA water research publications 1981-2010

attributed to the increase in coverage of water-related research by the WoS database and the greater increase in the number of publications in other countries.

\section{Impact}

Figure 4 shows the relative impact (relative citation index) of SA water publications in comparison to the average impact of all articles in the field. The impact is around 0.60 for most years in the period indicating that the country's water publications received fewer citations than the world average for the field. In 2010 there was an increase in the impact to 1.40. Annual variations usually reflect the effect of a small number of individual articles receiving a very high number of citations.

\section{Disciplinary and institutional assessment}

South Africa's share of world research publication (paper) outputs in selected scientific fields in shown in Table 1. The contribution to the 'water resources' literature by SA is $1.61 \%$, and there are a number of disciplines in which SA makes a greater contribution. Examples include religion, mining, mineralogy, ornithology, biodiversity and others. It has been argued that South African research has been, and still is, influenced by the availability of natural resources and the variety of flora and fauna (Pouris, 2008). Examples include the disciplines of mining and mineral processing, ecology, plant sciences, zoology and others. The activity indices show that South Africa is producing more than 9 times as much research in the field of religion than what is expected based on its relative size (as

\begin{tabular}{|c|c|c|}
\hline \multicolumn{3}{|c|}{$\begin{array}{l}\text { TABLE 1 } \\
\text { Share of research publications (papers) in selected } \\
\text { disciplines contributed by South Africa 2006-2010 }\end{array}$} \\
\hline Discipline & $\begin{array}{l}\text { Percentage } \\
\text { of papers in } \\
\text { field }\end{array}$ & $\begin{array}{l}\text { Activity } \\
\text { index }\end{array}$ \\
\hline Religion & 5.44 & 9.22 \\
\hline Area studies & 4.46 & 7.56 \\
\hline Mining and mineral processing & 3.99 & 6.76 \\
\hline Literature & 3.80 & 6.44 \\
\hline Ornithology & 3.76 & 6.37 \\
\hline Biodiversity conservation & 2.83 & 4.76 \\
\hline Archaeology & 2.74 & 4.64 \\
\hline Mineralogy & 2.68 & 4.54 \\
\hline Language and linguistics & 2.48 & 4.20 \\
\hline Entomology & 2.22 & 3.76 \\
\hline Ecology & 2.17 & 3.67 \\
\hline Tropical medicine & 2.17 & 3.67 \\
\hline Virology & 1.98 & 3.35 \\
\hline Geology & 1.91 & 3.23 \\
\hline Zoology & 1.89 & 3.20 \\
\hline Plant sciences & 1.67 & 2.83 \\
\hline Water resources & 1.61 & 2.72 \\
\hline Marine and freshwater biology & 1.52 & 2.57 \\
\hline Astronomy and astrophysics & 1.00 & 1.69 \\
\hline $\begin{array}{l}\text { Biotechnology and applied } \\
\text { microbiology }\end{array}$ & 0.82 & 1.39 \\
\hline $\begin{array}{l}\text { Meteorology and atmospheric } \\
\text { sciences }\end{array}$ & 0.74 & 1.25 \\
\hline Energy and fuels & 0.60 & 1.01 \\
\hline
\end{tabular}

manifested in the total number of publications produced by the country), and just below 7 times more research than expected in the field of mining. In the field of water resources South Africa is producing 2.72 times more than that expected on the basis of the country's gross research outputs.

Table 2 shows that South Africa produced 2323 publications in the field of water research during the period 1999-2010. The table indicates the categories of these publications. A large number of these publications were aligned to environmental sciences and environmental engineering. The classification is provided by Thomson-Reuters, and allows a particular journal to be assigned to more than one disciplinary category. Certain disciplines that may be of importance to the water field attracted little research, e.g., soil science, economics, management, and energy.

Table 3 shows the country's most prolific institutions in the field of water research. During the period 1999-2010 the most prolific producer of papers was the University of KwaZuluNatal, if one includes the papers produced by the University of Natal before it was renamed as the University of KwaZulu-Natal in 1996. The University of Pretoria is the next most prolific with 287 publications during the period. The University of Cape Town and CSIR follow with 239 and 183 publications, respectively. The table also reveals that the majority of research is undertaken at the country's universities. The research councils sector is represented in the list by the CSIR with 183 publications during the period. It should be noted that the Department of Water Affairs and Forestry appears in the list with 51 publications, as well as Umgeni Water, a state-owned entity involved in water management, with 31 publications. In South Africa, it 


\begin{tabular}{|l|c|}
\hline \multicolumn{2}{|c|}{$\begin{array}{c}\text { TABLE 2 } \\
\text { Science categories comprising SA water research } \\
\text { publications 1999-2010 }\end{array}$} \\
\hline Science categories (SCI) & $\begin{array}{c}\text { Number of } \\
\text { research } \\
\text { publications }\end{array}$ \\
\hline Water Resources & 2323 \\
\hline Environmental Sciences & 581 \\
\hline Engineering Environmental & 419 \\
\hline Geosciences Multidisciplinary & 316 \\
\hline Meteorology Atmospheric Sciences & 187 \\
\hline Engineering Civil & 148 \\
\hline Engineering Chemical & 76 \\
\hline Marine Freshwater Biology & 49 \\
\hline Agronomy & 42 \\
\hline Soil Science & 27 \\
\hline Ecology & 20 \\
\hline Limnology & 20 \\
\hline Oceanography & 18 \\
\hline Engineering Mechanical & 17 \\
\hline Chemistry Applied & 12 \\
\hline Economics & 12 \\
\hline Management & 12 \\
\hline Public Environmental Occupational Health & 10 \\
\hline Toxicology & 10 \\
\hline
\end{tabular}

\begin{tabular}{|c|c|}
\hline \multicolumn{2}{|c|}{$\begin{array}{c}\text { TABLE 3 } \\
\text { Prolific institutions contributing to SA water } \\
\text { research outputs } 1999-2010\end{array}$} \\
\hline Institutions & $\begin{array}{l}\text { Number of } \\
\text { research } \\
\text { publications }\end{array}$ \\
\hline Univ. Pretoria & 287 \\
\hline Univ. Cape Town & 239 \\
\hline CSIR & 183 \\
\hline Univ. KwaZulu-Natal & 180 \\
\hline Rhodes Univ. & 159 \\
\hline Univ. Witwatersrand & 148 \\
\hline Univ. Natal & 136 \\
\hline Univ. Stellenbosch & 133 \\
\hline Univ. Johannesburg & 94 \\
\hline Univ. Orange Free State & 91 \\
\hline Rand Afrikaans Univ. & 72 \\
\hline Univ. Western Cape & 54 \\
\hline Dept Water Affairs \& Forestry & 51 \\
\hline Tshwane Univ. of Technology & 39 \\
\hline Univ. Zululand & 39 \\
\hline Water Res Commission & 38 \\
\hline Potchefstroom Univ. & 35 \\
\hline Univ. Fort Hare & 35 \\
\hline Univ. Free State & 33 \\
\hline Univ. Venda & 32 \\
\hline Umgeni Water & 31 \\
\hline
\end{tabular}

is rare that government departments and parastatals undertake publishable research.

Figure 5 shows a time series for the most prolific producers of water research publications in South Africa. In 2010 the
Institution Performance - Water Research

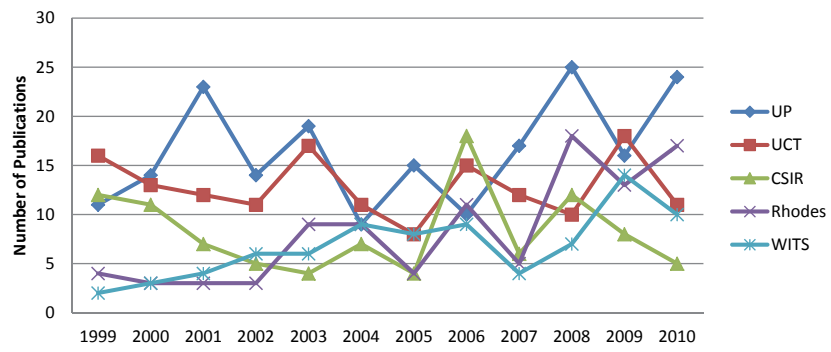

Figure 5

Prolific producers of water research: South Africa 1999-2010 UP - Univ. Pretoria; UCT - Univ. Cape Town; Rhodes - Rhodes Univ.; WITS - Univ. Witwatersrand

University of Pretoria produced the highest (24) number of publications followed by Rhodes University (17). It should be noted that all institutions produced fewer than 25 publications per year (less than 300 articles over the 12-year period) indicating a dispersion of expertise across a range of institutions and a lack of concentration and creation of critical mass. It should be noted that other disciplines are more concentrated at specific universities. For example, the University of Pretoria is producing more than $60 \%$ of the country's publications in veterinary medicine / animal health and more than $40 \%$ of SA's publications in the fields of metallurgy and engineering mathematics (Pouris, 2006).

It has been argued (Pouris, 2011) that political equity considerations in the country spill-over in the research domain as well. For example, research funders may tend to spread their resources thinly in order to support as many researchers as possible and avoid complaints. The policy question then is: can a country leap-frog its science and innovation system to catch up with the rest of the world and compete internationally through a 'distributed' approach or should it concentrate its limited scientific expertise in a limited, focused number of research centres?

Table 4 shows the research emphases of the various institutions. 'Environmental sciences' appears at the top of the list for 4 of the 6 institutions in the table. 'Geosciences multidisciplinary' is emphasised at the University of KwaZulu-Natal and the University of the Witwatersrand.

\section{Patents}

The patents most often utilised for patent analysis internationally are those granted by the United States Patent and Trademark Office (USPTO). Although most countries in the world have their own patent authorities, the use of the USPTO provides a number of advantages. Firstly, in a number of other patent offices, patents are not examined for originality, usefulness and novelty. This is also the case in South Africa (Pouris et al., 2011). Consequently, counting and comparing patents awarded by different patent offices in different countries may be misleading because of differences in the criteria used and the ease of awarding patents, bias towards local patents, etc. The obvious method to avoid the above-mentioned shortcomings is to use a common denominator, such as an external patent system with an objective approach in awarding patents (i.e. the USPTO).

Figure 6 shows the number of patents awarded to South Africans by the USPTO from 1981-2010. It also shows the South African share in foreign patents (non-USA) awarded by 
TABLE 4

Institutional emphasis: SA water resources publications

Institutional emphasis

\begin{tabular}{|c|c|c|c|c|c|}
\hline Science categories & $\%$ & Science categories & $\%$ & Science categories & $\%$ \\
\hline \multicolumn{2}{|l|}{ Univ. Pretoria } & \multicolumn{2}{|l|}{ Univ. Cape Town } & \multicolumn{2}{|l|}{ CSIR } \\
\hline Environmental sciences & $33.79 \%$ & Environmental sciences & $33.89 \%$ & Environmental sciences & $46.44 \%$ \\
\hline Engineering environmental & $28.92 \%$ & Engineering environmental & $28.03 \%$ & Engineering environmental & $38.25 \%$ \\
\hline Engineering chemical & $6.27 \%$ & Geosciences multidisciplinary & $7.53 \%$ & Geosciences multidisciplinary & $9.29 \%$ \\
\hline Geosciences multidisciplinary & $6.27 \%$ & Engineering civil & $4.18 \%$ & Marine freshwater biology & $7.65 \%$ \\
\hline Agronomy & $4.18 \%$ & Marine freshwater biology & $3.34 \%$ & Ecology & $6.01 \%$ \\
\hline \multicolumn{2}{|l|}{ Univ. KwaZulu-Natal } & \multicolumn{2}{|l|}{ Rhodes Univ. } & \multicolumn{2}{|l|}{ Univ. Witwatersrand } \\
\hline Geosciences multidisciplinary & $29.44 \%$ & Environmental sciences & $17.61 \%$ & Geosciences multidisciplinary & $23.64 \%$ \\
\hline Meteorology atmospheric sciences & $15.00 \%$ & Geosciences multidisciplinary & $16.35 \%$ & Engineering civil & $16.21 \%$ \\
\hline Environmental sciences & $12.22 \%$ & Engineering civil & $8.17 \%$ & Meteorology atmospheric sciences & $14.18 \%$ \\
\hline Engineering civil & $10.55 \%$ & Engineering environmental & $8.17 \%$ & Environmental sciences & $13.51 \%$ \\
\hline \begin{tabular}{|l|} 
Engineering environmental \\
\end{tabular} & $6.11 \%$ & $\begin{array}{l}\text { Meteorology atmospheric } \\
\text { sciences }\end{array}$ & $5.66 \%$ & Engineering environmental & $6.08 \%$ \\
\hline
\end{tabular}

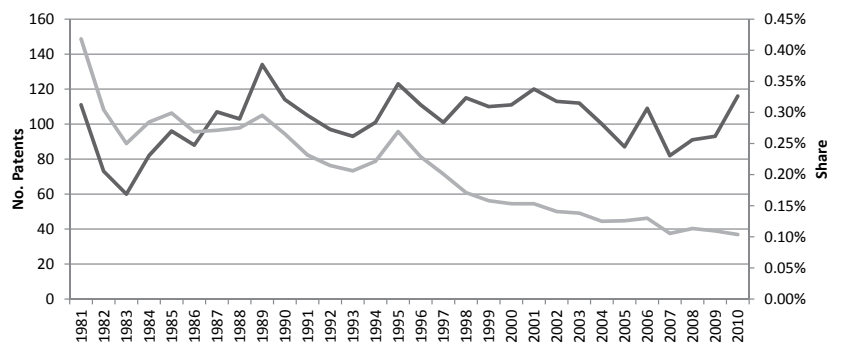

—SA - SA Share

Figure 6

Patents granted to SA inventors and SA share of all patents: USPTO 1981-2010

the USPTO. The past 2 years exhibit an increase in the number of patents awarded to South Africans and it appears that the long-term decline in the South African share of USPTO patents has been stabilised. It is still too early to draw any conclusions about trends from the most recent years. It is noticeable, however, that South Africa in general obtains very few patents in the USPTO. Companies like IBM are granted more than 3000 patents a year.

In order to identify the water-related patents granted to South African inventors by the USPTO the study utilised a search strategy identifying keywords in the titles (TTL) of patents. The search strategy was as follows:

TTL /(water OR desalination OR dewatering OR filtration OR (reverse AND osmosis) OR sludge OR purification OR catchment OR river OR sewage OR irrigate OR estuary OR wetland OR rainfall OR effluent)

Simultaneously the search was limited to South African inventors and to patents granted between 2000 and 2010.

Searches were made for assignees from South Africa with the word 'water' in the name.

The search identified 48 South African patents during the period. Visual inspection identified 6 false positives (i.e. patents that they are not necessarily related to water inventions such as swimming pool equipment, water vehicles, etc.)

Figure 7 shows the number of water-related patents awarded to South African inventors between 2000 and 2010. South African inventors received just above 4 water-related patents per year on average. The study also identified the assignees of the South African patents. The assignees with the

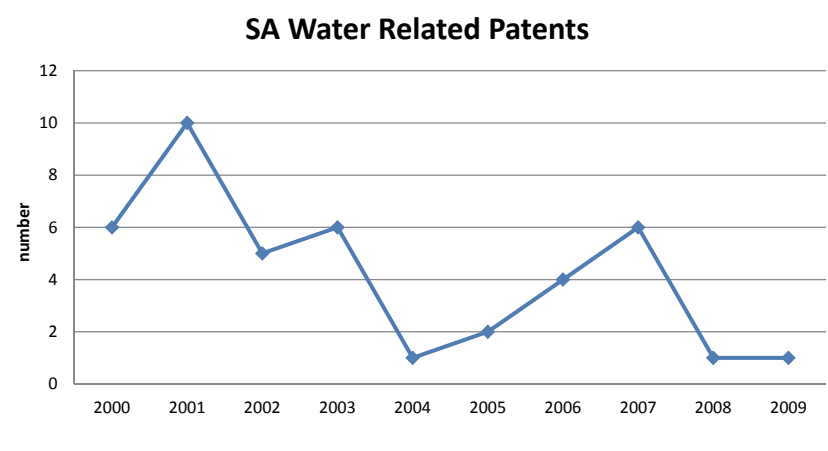

Figure 7

SA water-related patents granted by USPTO: 2000-2010

most water-related patents are the Water Research Commission and Sasol Technology (Pty) Ltd with 7 patents each. The CSIR follows with 4 patents during the period. Additionally, a keyword density analysis revealed that apart from the word 'water' the most frequent words were: 'treatment' (6.5\%); 'method' (4.2\%); purifying (2.8\%); Fisher Tropsch (2.7\%); filtration (2.3\%) and sulphate (1.4\%).

Interestingly, Table 5 shows that water-related patents comprise a greater percentage of the total patents granted for South Africa than is the case for the other countries listed. The table shows the BRIC countries as well as a number of countries prolific in granted patents.

\begin{tabular}{|l|c|c|c|}
\hline \multicolumn{4}{|c|}{ TABLE 5 } \\
Water-related patents as a percentage of total granted \\
patents: 2000-2010
\end{tabular}




\section{CONCLUSION}

The bibliometric analysis identifies that South Africa's water field is performing above expectation in comparison with the country's research size (activity index). It can be argued that this performance is the result of the existence of a dedicated agency that supports the research enterprise in the country the Water Research Commission.

International comparisons, however, show that a number of countries with smaller populations, and smaller GDPs per capita, produce more water-related knowledge than South Africa. Identification of the country's producers of research in the field shows that the country's water research is distributed to a variety of centres creating subcritical groups. In other countries individual institutions produce as many research publications as a number of South African universities together. This raises an important policy issue, as discussed in the previous section, with possible adverse consequences for research productivity and economies of scale.

Environmental sciences are identified as the most important sub-discipline in the field of water resources. Certain disciplines that may be of importance for the field, e.g., economics, management and energy, attract little research.

The disciplinary emphases of the country's institutions indicates that researchers move on their own to specific areas without any particular guidance or cognisance of priorities/ diversification. It will be important for the WRC to identify research priorities through appropriate approaches (e.g. foresight) and allocate resources accordingly to promising areas. Such an approach will focus resources (human and financial) to areas of importance and has the potential to bring research closer to application.

The patent analysis also identifies that South Africa is producing a greater proportion of water-related inventions, relative to its total patent output, than the comparator countries. However, it should be noted that South Africa is granted a very small number of patents in general from the USPTO.

A number of issues require further research. Examples include: what is the WRC's contribution to the country's research outputs (additional evidence is required); what is the detrimental impact (if any) of the distributed research approach used in the country? Are the revealed research priorities (as manifested in disciplinary outputs) in accordance with opinion-based priorities? Finally, it is important to link funding modes with the relevant research outputs.

\section{ACKNOWLEDGEMENTS}

This article is based on a Water Research Commission report. The article has benefited from comments of anonymous reviewers. The normal caveats apply.

\section{REFERENCES}

DASTIDAR P and RAMACHANDRAN S (2005) Engineering research in ocean sector: An international profile. Scientometrics $\mathbf{6 5}$ 199-213.

DE SOLLA PRICE D (1975) The productivity of research scientists. In: Yearbook of Science and the Future, Encyclopaedia Britannica Inc. University of Chicago, Chicago.

EC (EUROPEAN COMMISSION) (1997) Second European Report on S\&T Indicators. European Commission, Directorate General XII, Science, Research and Development, Brussels.

GRILICHES Z (1990) Patent statistics as economic indicators: A survey. J. Econ. Lit. 28 1661-1707.

JEENAH M and POURIS A (2008) South African research in the context of Africa and globally. S. Afr. J. Sci. 104 (9/10) 351-354.

NSB (NATIONAL SCIENCE BOARD) (2010) Science and Engineering Indicators - 2010. National Science Board, VA. National Science Foundation, Arlington.

OECD (ORGANISATION FOR ECONOMIC CO-OPERATION AND DEVELOPMENT) (1994) The Measurement of Scientific and Technological Activities, Using Patent Data as Science and Technology Indicators - Patent Manual. OECD, Paris.

OECD (ORGANISATION FOR ECONOMIC CO-OPERATION AND DEVELOPMENT) (2002) Frascati Manual (6 $6^{\text {th }}$ edn). OECD, Paris.

OECD (2004) Patents and Innovation: Trends and Policy Challenges. OECD, Paris.

OECD (ORGANISATION FOR ECONOMIC CO-OPERATION AND DEVELOPMENT) (2010) Main Science and Technology Indicators. OECD, Paris.

OST (OBSERVATOIRE DES SCIENCES ET DES TECHNIQUES) (2008) Science and Technology Indicators. OST, Paris.

PORTER ME, SCOTT S and COUNCIL ON COMPETITIVENESS (1999) The New Challenge to America's Prosperity: Findings from the Innovation Index. Council on Competitveness, Washington.

POURIS A (1988) Peer review in scientifically small countries. R\&D Manag. 18 (4) 333-340.

POURIS A (2005) Transport research in South Africa: A quantitative assessment. Sci. Public Polic. 32 1-4.

POURIS A (2006) Assessing scientific strengths of academic institutions: the University of Pretoria. S. Afr. J. Sci. 102 23-26.

POURIS A (2008) Energy \& fuels research in South Africa: A comparative assessment and mapping. Open Inf. Sci. J. 1 1-9.

POURIS A and POURIS A (2011) Scientometrics of a pandemic: HIV/ AIDS research in South Africa and the World. Scientometrics $\mathbf{8 6}$ 541-552.

POURIS A and POURIS A (2011) Patents and economic development in South Africa: Managing intellectual property rights. S. Afr. J. Sci. $107(11 / 12) 1-10$.

POURIS A (2012) Science in South Africa: The dawn of renaissance? S. Afr. J. Sci. 108 (7/8) 66-71.

ROJO R AND GOMEZ I (2005) Analysis of the Spanish scientific and technological output in the ICT sector. Scientometrics 66 101-121. 
http://dx.doi.org/10.4314/wsa.v40i4.8 Available on website http://www.wrc.org.za 